
AJIS Special Edition
Knowledge Management
December 2001

\title{
IMPEDIMENTS TO INTER-FIRM TRANSFER OF BEST PRACTICE IN AN ENTERPRISE SYSTEMS CONTEXT
}

\author{
Greg T Timbrell \\ Natalie $M$ Andrews \\ Guy G Gable \\ Information Systems Management Research Centre \\ Queensland University of Technology \\ g.timbrell@qut.edu.au
}

\begin{abstract}
A survey of major issues with Enterprise Systems was administered within the State Government of Queensland, Australia and a subset of these issues mapped against Szulanski's model of inter-firm best practice transfer stickiness (Szulanski, G. 1996. Exploring internal stickiness: Impediments to the transfer of best practice within the firm. Strategic Management Journal, 17(Special Issue), 27-43). The paper discusses impediments to knowledge transfer within this context, presents findings from the a posterioni application of Szulanski's model to the survey responses, and suggests future research directions.
\end{abstract}

Keywords: ERP, enterprise systems, knowledge management, knowledge transfer, consulting

\section{INTRODUCTION}

A parent study, "Cooperative enterprise system life-cycle knowledge management" (Gable et al, 1998) explores means of better managing knowledge across the three key players involved in Enterprise Systems life-cycle support the client, vendor and implementation partner. Herein we explore knowledge transfer issues in the Enterprise Systems (ES) context.

An early stage of the parent study entailed a study of major issues within the Queensland State Government in Australia. Through a modified Delphi approach, personnel that had been involved in implementation and management of the common ES - SAP R/3, were surveyed to determine what major issues they had experienced with the system. Implementation partners were also asked to furnish major client-issues.

The survey was piloted in five agencies (for discussion of methodological issues related to the pilot study see Chang et al, 2000), then extended to the rest of the Queensland Government. From the extension study 479 knowledge transfer related survey responses were identified, then mapped against Szulanski's model of Intra-Firm Transfer Of Best Practice (Szulanski, 1996) in order to explore barriers to knowledge transfer on ES implementations.

This paper firstly describes why knowledge transfer in an ES context is important. We then provide a literary overview of knowledge transfer, including a description of Szulanski's model. After briefly recounting the pilot mapping exercise to Szulanski's model and some preliminary results we lastly suggest future research directions.

\section{KNOWLEDGE TRANSFER IN THE ENTERPRISE SYSTEMS CONTEXT}

\section{Enterprise Systems}

A new class of packaged application software has emerged over the past decade, ostensibly consolidating under a single banner, a multi-billion dollar industry that includes SAP AG, the world's fourth largest software vendor, several other of the largest software firms and the world's largest management consulting organisations. Variously called enterprise resource planning systems (ERP), enterprise-wide systems, or simply enterprise systems (ES), these comprehensive, packaged software solutions seek to integrate the complete range of a business's processes and functions in order to present a holistic view of the business from a single information and IT architecture (Gable et al, 1998; Klaus et al, 2000).

According to Chan (1999), ES implementations require a wide range of knowledge including project knowledge (how to implement ES, business process engineering, change management, training and education), technical knowledge (such as programming, system and database administration), product knowledge (specifics of the ES) and business knowledge ( $\ldots$ of the business, it's culture and people). Where an organisation does not have the requisite knowledge, it will often seek this implementation knowledge from third-party providers. Implementation resources are predominantly knowledge based. This knowledge may be sourced from a (typically large) consulting firm (knowledge vendor), which acts in the capacity of implementation partner. Sharing the joint objective of successful 
implementation and in some cases, ongoing management, an alliance is formed between the client organisation, the ES software vendor, and this third-party.

Having engaged a suitable implementation partner, the client completes the implementation process, goes live with the ES and moves into the post-implementation maintenance and upgrade cycle. At the end of the implementation phase, the consultant usually withdraws from the organization. Responsibility for managing the ES falls back to the client. Continuing success of the ES becomes reliant on the client's skill and knowledge in operating, maintaining and upgrading the ES. In order to keep the ES 'live' and relevant, the client must either draw from their ES capabilities transferred-in during the implementation period or seek expert support (knowledge) externally. Such external support is usually available from the vendor, the implementation partner and other third parties and is often expensive.

Organisations planning to support the ES in-house (insourcing) face the issue of attracting or developing, then retaining staff with the necessary knowledge. Where the client plans to outsource its ES to an Application Service Provider (ASP), post-implementation ES knowledge self-sufficiency may not be necessary. ASP vendors cite this alleviation of 'future skills risk' as one of their competitive advantages (Bennett and Timbrell, 2000). On the other hand, should the organisation follow an insourcing strategy, then it will often aspire to post-implementation ES knowledge self-sufficiency, in order to reduce reliance on third-party support and the associated high costs of that support. Knowledge management, and knowledge sharing in particular, is considered to offer significant commercial and practical benefits throughout the ES life-cycle (Gable et al, 1998). It can be argued, therefore, that knowledge transfer from vendor and implementation partner to the client organisation is an important factor in ES life-cycle management. In the case of a client organisation outsourcing their ES to an ASP, Feeny and Willcocks (1998) suggest that consideration be given to what knowledge or competencies should be developed or retained in-house.

According to Davenport (2000), client organisations often experience poor ES implementations because they regard the project as a one-time exercise and so fail to attend to ES knowledge management issues, such as requesting (contracting for) knowledge transfers from consultants, or adequately maintaining the transferred knowledge. While the current literature falls short of empirically demonstrating causal links between effective knowledge transfer and successful ES implementations, the expectation is that knowledge transfers leave the client organisation better positioned to maintain and evolve their system, and to generate returns from the ES investment (Davenport, 2000). This project and its umbrella research program attempt to bridge this gap in the literature.

However the mere possession of transferred knowledge is unlikely to be sufficient to meet a client's independence objectives. Effective knowledge transfer requires not only transmission, but also knowledge absorption and use (Davenport and Prusak, 1998). Developing the capability to effectively maintain and leverage knowledge will depend on the client's ability to either integrate new ES knowledge with knowledge of the business or combine it with existing capabilities. This knowledge must then be used to create appropriate routines and capabilities in support of business objectives (Andreu and Ciborra, 1996; Kogut and Zander, 1993; Inkpen and Dinur, 1998). Organisational capability emerges over time through a process of organisational learning (Levitt and March, 1988). It is informative then, to examine the literature regarding the transfer of knowledge into and within the firm for purposes of organisational learning.

\section{Knowledge Transfer}

According to Nonaka (1994), organisational learning depends fundamentally on the internalisation of knowledge where explicit (formalised, explicated) knowledge is converted into tacit forms such as individual know-how and organisational routines. The knowledge is literally absorbed through action or experience.

Inkpen (1996) extends this notion by arguing that capability development in an alliance-context is therefore dependent on the integration of internalised knowledge from external sources into organisational routines. Thus, in an ES implementation, knowledge sourced from the implementation partner and the vendor must be translated, adapted and combined with knowledge of the organisation's business processes, then internalised into new organisational routines specific to the organisation's context.

The resource-based view of the firm emphasises leveraging of the firm's resources to develop organisational capabilities, and exploiting these to the firm's advantage. Andreu and Ciborra (1996) discuss the importance of situated learning and knowledge accumulation in the capability development process. Their work is notable for its focus on the role of context in organisational learning loops. They posit that the more path-dependent the learning process to develop work practices, routines and capabilities, the more idiosyncratic they are to the firm, and therefore, the less generalisable and transferable to different organisational contexts. Over time, business environments and their apposite legacy or ES, develop firm specific peculiarities. 
Constantly faced with implementing ES in unique and distinctive business environments, consultants sieve their experiences in a systematic way to extract idiosyncrasies from their ES client encounters thereby providing broad methodologies for general application to future ES clients. Consulting firms go to great lengths and expense to externalise ES knowledge in order to achieve a comparative advantage and to leverage their costly people (Timbrell and Gable, 2001). Vendors also are adopting this approach incorporating industry templates and reference process models into their product offerings. Both consultant and vendor are looking to record their implementation experiences for the development of best practice implementation methods. These methods increase consulting firms' net value-add during future implementations by improving completeness and quality, expediting implementation (reducing client costs), and/or allowing the deployment of less experienced (less expensive) consulting staff.

\section{SZULANSKI'S MODEL}

A different approach to knowledge transfer underpins research by Szulanski (1995) who uses a (Shannon and Weaver, 1949) communications metaphor to analyse intra-firm transfer of best practice in a manner analogous to the transmission of a message from a source to a recipient within a given media or context. Szulanski argues however that while knowledge transfer is a distinct experience rather than diffusion, best practice transfer should be regarded primarily as a process, rather than a transaction or event. Best practice transfer thus unfolds over four stages through which organisational routines are replicated. Initiation is defined as comprising "....all events that lead to the decision to transfer"; Implementation "... begins with the decision to proceed"; Ramp-up "...starts when the recipient starts using transferred knowledge"; and Integration "...begins after the recipient achieves satisfactory results with the transferred knowledge" (Szulanski, 1996, pp.28-29).

The significance of Szulanski's work is his analysis of the effects of certain characteristics of the context, the source, the recipient, and the message itself (ie. the knowledge or practice) in generating "noise" at various stages of the transfer process. Szulanski argues that the successful transfer of best practices should begin by assessing the origins of transfer difficulty and then incorporating selective interventions aimed at the most significant barriers.

An understanding of the types of mechanisms that have been empirically and theoretically demonstrated as potential barriers and facilitators of knowledge transfer may thus prove instructive when identifying the key issues at play in the particular case of ES knowledge transfers. To provide structure to this analysis, we draw from knowledge management and other literature, using Szulanski's model as a framework against which four categories of knowledge transfer mechanisms are examined.

Beginning from the premise that the transfer of best practices inside the firm can be "sticky" or difficult, Szulanski explored the origins of internal stickiness in an intra-firm context $(1995,1996,2000)$. His model is illustrated in the following diagram.

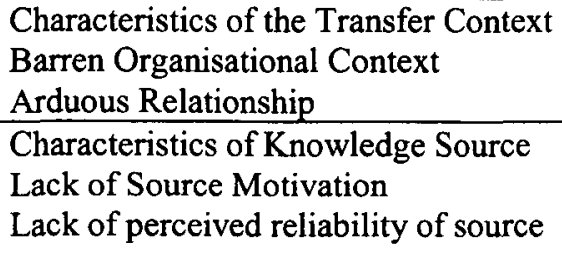

\author{
\begin{tabular}{l|l} 
Characteristics of Knowledge & Characteristics of Knowledge Recipient
\end{tabular} \\ Unproven Knowledge \\ Causal Ambiguity
}

Table 1: Szulanski's Origins of Knowledge 'Stickiness'

\section{Characteristics of the Knowledge}

Causal ambiguity signals the absence of know-why ... why something is done, and why a given action results in a given outcome (Szulanski, 1995). Szulanski found causal ambiguity to be a significant origin of stickiness through all phases of the transfer process and particularly important during the first three stages. Lippman and Rumelt (1982) argued in their theory of uncertain imitability that causal ambiguity may impede the precise replication of knowledge in a different setting by obscuring effects of idiosyncratic features of the new context in which the knowledge is used. Difficulty in replicating a capability can arise from ambiguity about the elements of success or failure and how they interact. Szulanski (1995) also found that proof of the usefulness of the source's knowledge is most important during the first two stages of the knowledge transfer process. The less substantiated the knowledge or the greater the speculation about claims it will solve the recipient's problem ("Unproven knowledge"), the more difficult it will be to induce the recipient to engage in the transfer. 


\section{Characteristics of the Source of Knowledge}

Szulanski's research also supported the notion that stickiness may derive from lack of source motivation to engage in knowledge transfer. The source may be reluctant to share for fear of losing ownership or privilege, they may perceive inadequate rewards for sharing, or they may be unwilling to commit time and resources to the transfer.

Confirming Arrow's (1971) view, Szulanski also found lack of perceived reliability of the source to be an important origin of stickiness early in the initiation stage. Szulanski draws on persuasion theory in associating reliability with expertise and trustworthiness and notes that where these are perceived as lacking, transfer may be sticky and the source's advice challenged and resisted. Davenport and Prusak (1998) support this argument, noting that people judge knowledge according to the status and reputation of its source.

\section{Characteristics of the Recipient of Knowledge}

Szulanski's research confirmed the popular notion that a lack of recipient motivation to accept knowledge from an external source and engage in particular activities that require its use will present stickiness. Interestingly, he found not only that knowledge-related variables were more important barriers than motivation, but also that a motivated recipient may add to transfer difficulty. This is because impatiently enthusiastic recipients embraced transfers without meticulous planning, resulting in cost and time overruns.

Lack of absorptive capacity of the recipient was strongly supported in Szulanski's research as a major barrier to knowledge transfer, particularly during the implementation phase. Cohen and Levinthal (1990) found that a recipient's stock of prior related knowledge determines their absorptive capacity for new knowledge, and deficiencies can render the recipient unable to successfully exploit new knowledge. Aside from basic skills, important prior knowledge may include a shared language, previous relevant experience and knowing where to find complementary expertise.

The recipient's ability to retain transferred knowledge through institutionalizing its use, reflects retentive capacity. If this ability is lacking then difficulties in integrating knowledge may result in failure to persist in using it and even reversion to the status quo (Zaltman et al, 1973). Szulanski (1995, p.122) confirmed lack of recipient retentive capacity as a cause of stickiness and argued that overcoming this barrier may require unlearning routinised use of prior knowledge.

\section{Characteristics of the Transfer Context}

Recognising the importance of organisational context to the gestation and evolution of a transfer initiative, Szulanski described as 'fertile' or 'barren' those contexts that either facilitate or impede the number and fate of knowledge transfer attempts. His research confirmed barren organisational context as an important origin of stickiness during the ramp-up and integration phases.

Davenport and Prusak (1998) discuss several cultural factors that may inhibit knowledge transfer, such as lack of trust; different cultures, vocabularies and frames of reference; lack of time and meeting places; a narrow idea of productive work; status and rewards accruing to knowledge "owners"; "not-invented-here" syndrome; and, intolerance of mistakes or need for help. Above all else, they emphasize the importance of trust and common ground in facilitating knowledge transfer. "The closer people are to the culture of the knowledge being transferred, the easier it is to share and exchange" (p. 100). Szulanski's research found that an arduous relationship - "laborious and distant" (1996, p.32) between source and recipient increases difficulty during the implementation phase of knowledge transfer, when interaction is at its most intense. This has notable implications for tacit knowledge transfer, which may necessitate numerous individual exchanges (Nonaka, 1994).

Overall, Szulanski's (1995) empirical results from study of the origins of internal stickiness suggest that the major barriers to intra-firm knowledge transfer were lack of absorptive capacity on the part of the recipient, causal ambiguity with regard to the knowledge itself and an arduous relationship between the source and the recipient.

\section{DATA COLLECTION AND METHODOLOGY}

A survey was conducted of staff in Queensland Government Agencies who were involved in the implementation of SAP R/3, the government-wide standard ES. Staff were asked "What do you consider have been the major issues in implementing, managing and/or supporting the SAP Financials in ... (your Government) Agency?" 
We classified these survey responses using a rules-based method (see Appendix One) where individual responses were coded to Szulanski's stickiness and transfer phase constructs. Szulanski's constructs break down into a series of statements that were modified for the purposes of this analysis.

In adapting Szulanski's (intra-firm) instrument we removed statements purely relevant to internal transfers to establish its relevance to an inter-firm transfer context. For example, Szulanski's original statement " $A t<<$ company>> despite structural differences units can always learn from one another", was changed to "Low acceptance for copying and adapting knowledge or practices". To further assure this process, Szulanski's original literature review was systematically revisited in order to confirm the theoretical basis for each statement.

In Szulanski's original instrument he included an open-ended question about the most important difficulty experienced in transfer (1995, pp.127-128). Some example responses from this open-ended question were incorporated in our coding instrument. For instance, "nobody fully understood the concept" was classified by Szulanski under Causal Ambiguity and so we added this to our coding table (see Appendix One).

A final adaptation of Szulanski's instrument was the modification of his statements so that each was expressed as a barrier to knowledge transfer in our coding method. For example, "the limits of the knowledge or practice are fully specified" was changed to "limits of the knowledge or practice were not fully specified". Consequently, the survey responses (which express issues related to ERP) were coded to transfer phases or stickiness origins only if they conveyed elements of difficulty or stickiness in transfer. Our modified codification instrument is attached as Appendix One.

A relatively simple procedure was used to classify the responses against Szulanski's framework. Each issue raised was considered in the context of its accompanying narrative description. Codes were assigned (e.g. CA -5 meaning Causal Ambiguity reference statement 5) according to the constructs reflected and the instrument reference number applicable to the issue. The aim was to assign at least one code to represent the transfer phase to which the issue referred, and to identify at least one stickiness origin, on the premise that a knowledge transfer is defined as sticky when it is "worthy of remark" or "eventful" (Szulanksi, 1995a, p21). There was no upper limit on the number of codes assigned per issue, this being driven by the data itself. Ultimately, each original issue was associated with (coded to) one or two transfer phases; and one, two or three stickiness origins. This process effectively "decomposed" compound statements reported within a single "issue", thereby providing a means of addressing respondents' differing writing styles (i.e. reporting multiple items against the one "issue" versus reporting them as separate "issues").

On occasion it was necessary to interpret a remark based on other issues raised by the same respondent. For example, "availability of skilled SAP resources" was classified under Barren Organisational Context when considered in relation to further comments by the same respondent. In this instance other issues cited by the same respondent related to the Barren Organisational Context and included "awareness of the project and SAP in the organization" and "communication within the project".

The codes assigned to each issue were then entered into a relational database and data analysis was subsequently performed to identify the incidence of stickiness origins reported for each transfer phase.

The rules-based approach employed in this mapping exercise is summarised forthwith:

- Is it a knowledge related issue?

- Is there a direct, potential or inferred barrier? When did this happen? ie. Fixing the potential barrier would have resulted in a better [lifecycle] phase.

- Is it relevant to knowledge transfer?

- To what phase / outcome does this issue apply?

- To what characteristic of knowledge or transfer participant or context does this issue apply?

- Reference the data set of other issues reported by the same respondent if further clarification is required.

\section{FINDINGS}

Four hundred and seventy-nine (479) survey responses were assigned codes representing potential stickiness origins using the rules-based classification method. Many of the survey responses contained multiple issues as well as issues that were be assigned multiple codes for both the transfer phase and the stickiness origin. The following table sets out the totals of phase and stickiness origin assignments: 


\begin{tabular}{|l|l|l|l|l|}
\hline Coding Assignments & 1st Stickiness Origin & 2nd Stickiness Origin & $\begin{array}{l}\text { 3rd Stickiness Ori- } \\
\text { gin }\end{array}$ & Total \\
\hline 1st Transfer phase & 479 & 233 & 64 & 776 \\
\hline 2nd Transfer phase & 81 & 48 & 20 & 149 \\
\hline Total & 560 & 281 & 84 & 925 \\
\hline
\end{tabular}

Table 2: Assignments of Transfer phase and Stickiness origins to issues

Stickiness instances were then mapped against their associated transfer phases. Table 2 compares Szulanski's findings with findings from this study and suggests the order of importance of the stickiness origin within each transfer phase based on counts. Following we discuss only extreme cases of either accord or discord between Szulanski ranks and our study counts. Note that there are insufficient counts from our mapping of issues to draw any conclusions about ES knowledge transfer in the Initiation Phase. This is because there was only a limited number of people within the Queensland Government involved in the initiation (selection, planning) of the common SAP R/3 ERP.

Using regression analysis, Szulanski calculated the standardized beta coefficients for each of his stickiness origins within each transfer phase. In example the regression equation for the 'implementation' phase is ...

Stickiness Implementation $\quad=\mathrm{bl}{ }^{*} \mathrm{~K}$ nowledgeCausal Ambiguity

+ b2*Knowledge Unproven Knowledge

+ b3*Source Lack motivation

+ b4*SourceLack perceived reliability

+ b5*RecipientLack motivation

$+\mathrm{b} 6{ }^{*}$ RecipientLack Absorptive Capacity

+ b7*RecipientLack retentive capacity

$+\mathrm{b} 8 *$ ContextBarren

$+b 9 *$ Relationship Arduous.

Table 3 (adapted from Szulanski, 1995:pp89\&91) displays the ranks of only the beta coefficients Szulanski found to be significant in each phase (ranks being based on the relative size of the betas with the largest beta being ranked 1). From Szulanski's ranks in Table 3 we see that Causal Ambiguity was found to be an important origin of stickiness across all transfer phases (included in the regression equation for all four phases and ranked 3rd, 2nd, 3rd and 4th most important of the 9 origins). Our counts however do not support this finding (based on this study's counts, Causal-Ambiguity is not ranked in the top 4 in any transfer phase). It is suggested that in an ES setting the rationale for an action and the explanation of the resultant outcome are usually clear. In the absence of such rationale the ES processes would be highly questionable in an organisational setting.

Transfer Phases

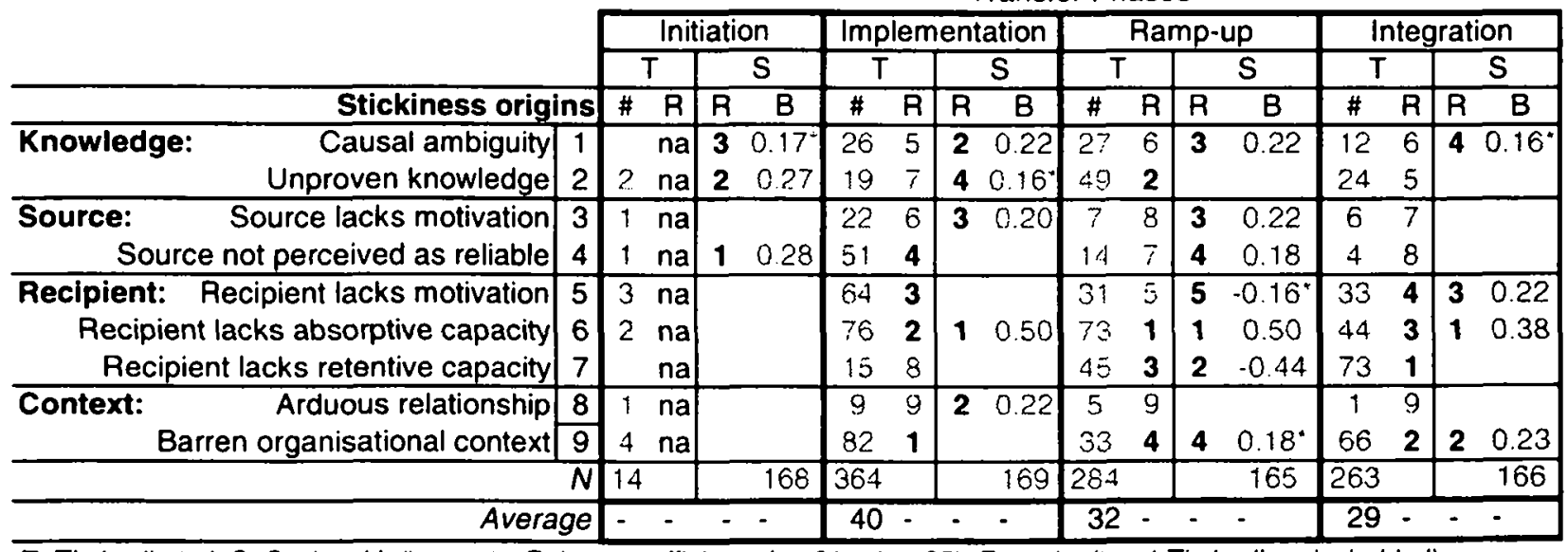

$T=$ Timbrell et al, $S=S z u l a n s k i, \#=$ counts, $B=$ beta coefficients $\left(p<.010\right.$ r $^{*} p<.05$ ), $R=$ ranks (top 4 Timbrell ranks bolded)

Table 3: Incidence of Stickiness, by Origin, by Transfer Phase

Unproven knowledge was found by Szulanski to be important in the first two transfer phases (2nd and 4th). Our counts suggest that Unproven Knowledge is important in the 3rd phase i.e. Ramp-up (ranked 2nd). It is during this stage that users first experience information from the system through reports. If this information is (or is perceived to 
be) inaccurate, users begin to doubt the usefulness of the ES and speculate on its ability to solve their information needs.

Source lacks motivation was found to be an important origin of stickiness during the implementation (3rd) and rampup (3rd) stages in Szulanski's study. Our counts do not support this finding suggesting that the main knowledge sources, vendor, consultant, business areas and implementation team, are sufficiently motivated to share their knowledge in order to meet the organisation's objective of an effective ES.

Source not perceived as reliable was found by Szulanski to be 1st and 4th most important in the Initiation and Rampup phases respectively, whereas our study counts suggest this to be the 4th most important origin of stickiness during Implementation and relatively unimportant during other phases. A possible explanation is that users did not regard some junior consultants as sufficiently expert to implement or support SAP in a complex organisational context.

Szulanski's ranks (5th and 3rd) and those from this study (5th and 4th) for Recipient lacks motivation are highly similar for the Ramp-up and Integration phases. Unlike Szulanski's study, in this study, this stickiness source ranks high (3rd) in the Implementation phase. During implementation the recipient client organisations demonstrated their lack of motivation in several ways: insufficient resources allocated to the project, rushed and unplanned ES introduction and poor stakeholder and executive support.

We note especially strong correspondence between the Szulanski findings and our study counts on Recipient lacks absorptive capacity which on Szulanski's data ranks 1st in each of the latter 3 transfer phases, and ranks 2nd, 1st and 3 rd based on our study counts (counts of 76,73 and 44 ). This might be explained by the relative complexity of the $\mathrm{ES}$, an issue that consistently arose in the major issues study conducted in the Queensland Government. Szulanski ranks recipient lacks retentive capacity high (2nd) in Ramp-up only. Our data suggest this source of stickiness is important (1st) during Integration as well. We note that users experienced much difficulty unlearning old processes and system functions.

Barren organizational context was ranked 1st in our counts during the implementation stage, 4th during ramp-up and 2nd in the integration phase. While there is close correspondence with Szulanski's ranks during ramp-up and integration (also 4th and 2nd) our finding for the implementation stage conflicts with Szulanski's finding. Drivers for this measure include poor executive and stakeholder support, poor planning, training and change management.

Finally, Szulanski ranks Arduous relationship 2nd during Implementation, whereas our counts are low on this origin, for all transfer phases.

A common indication from both studies is the problem of deficient absorptive capacity of knowledge recipients across the phases of implementation, ramp-up and integration. This suggests we concentrate our further analytical efforts on the recipients of knowledge, and specifically their preparedness and ability to accept and absorb ES knowledge.

Origins of stickiness frequently cited in the current study (high counts), but not ranked highly by Szulanski include source not perceived as reliable (Implementation) and recipient lacks retentive capacity (Integration). The former may reflect the serious dearth of ES expertise at the time of most Queensland Government implementations and the concurrent general insufficiency of product knowledge across all involved (including vendor and implementation partner staff). It would appear that both studies identify lack of retentive capacity as a major problem in Ramp-up and Integration. This problem would not be as apparent in the earlier transfer phases, we speculate may be endemic to the Enterprise System life-cycle. Again the findings suggest a research focus on the recipients of ES knowledge and their ability to retain that knowledge as well as unlearn legacy system behaviors. Finally our counts indicate the importance of organizational context, support from management in both resources and endorsement of the ES, in enabling knowledge transfer.

\section{CONCLUSION}

While Szulanski's research empirically tested the constructs, the data collection and analysis methods followed in the present study diverged markedly from Szulanski's approaches, with uncertain effect on the validity of the findings as they are presented above. Szulanski's method was based on a detailed questionnaire with a multi-item ordinal scale limiting the responses particular to each construct. In contrast the present study generated qualitative data from a single open-ended question. Szulanski's measurement items for each construct were modified for applicability to the present study's context and data collection approaches. No explicit testing of the internal or external validity of the modified scale used in the present data analysis method was undertaken.

The effects, if any, that these factors may have had on the validity of the coding instrument for classifying the openended qualitative responses from the survey are unknown. Because of the care taken in making the modifications described in Part 4 the effect is expected to be minimal. It is acknowledged that the Delphi approach was deliberately chosen to generate issues important from the participants' perspectives. 
Further aspects of the analysis method raise uncertainty regarding reliability. Classification of the issues raised in the responses was inherently a subjective process open to analyst bias, since it involved the interpretation of qualitative data. To enable review by other analysts, raw data was coded to a level of detail that depicts the particular measurement items considered relevant in identifying each construct chosen for an issue. Re-coding of the data set by a range of other analysts would reveal the degree to which the results are consistent when the process is repeated. There was no comparative method for rating stickiness strength or weakness, nor the degree of a particular stickiness origin's influence.

In summary, further analysis of validity and reliability of the analysis methods would be appropriate before generalising to other ES knowledge transfer situations. Nonetheless, the findings as presented are interesting in two respects. Firstly, they reveal important insights into the variables that may have directly or indirectly presented barriers to knowledge transfer in the ES implementations responsible for the source data. Secondly, the pattern of apparently significant barriers at each transfer stage suggests interesting similarities and differences when compared with Szulanski's findings of intra-firm transfer stickiness.

\section{REFERENCES}

Andreu, R. \& Ciborra, C. (1996) "Organisational learning and core capabilities development: The role of IT," Journal of Strategic Information Systems Vol 5, pp 111-127.

Arrow, K. (1971) Classificatory notes on the production and transmission of technical knowledge, Amsterdam, Holland.

Bennett, C. \& Timbrell, G. (2000) “Application Service Providers: Will They Succeed?" Information Systems Frontiers, Vol 2, No 2, pp 195-211

Chan, R. (1999) “Knowledge management for implementing ERP in SMEs," Proceedings of the 3rd Annual SAP Asia Pacific Conference, Singapore.

Chang, S., Gable, G., Smythe, E. \& Timbrell, G. (2000) “Methods for distilling key issues using a delphi approach", Proceedings of the 11th Australasian Conference on Information Systems, 6-8 December, Brisbane, Australia.

Cohen, W. M. \& Levinthal, D. (1990) "Absorptive capacity: A new perspective on learning and innovation," Administrative Science Quarterly, Vol 35, No 1, pp 128-152.

Davenpor, T. H. (2000) Mission Critical: realizing the promise of enterprise systems, Boston, MA, HBS Press.

Davenport, T. H. \& Prusak, L. (1998) Working knowledge: How organizations manage what they know. Boston, MA. Harvard Business School Press.

Feeny, D. \& Willcocks, L. (1998) "Re-designing the IS Function around Core Capabilities", Long Range Planning, Vol 31 No 3, pp 354-367.

Gable, G. G., Scott, J. \& Davenport, T. (1998) “Cooperative EWS life-cycle knowledge management”, Proceedings of the Ninth Australian Conference on Information Systems, 29 September - 2 October, Sydney, Australia, pp 227-240.

Inkpen, A. C. (1996) “Creating knowledge through collaboration”, California Management Review, Vol 39, No 1, pp 123-140.

Inkpen, A. C. \& Dinur, A. "The transfer and management of knowledge in the multinational corporation: Considering context”. Working Paper 98-16. Carnegie Bosch Institute. 1998.

Klaus,H., Rosemann, M. \& Gable, G.G. (2000) “What is ERP?”, Information Systems Frontiers, Vol 2, No 2, pp 141-162.

Kogut, B. \& Zander, U. (1992) "Knowledge of the firm, combinative capabilities and the replication of technology", Organization Science, Vol 3, No 3, pp 383-396.

Levitt, B. \& March, J.G. (1988) “Organizational learning," Annual Review of Sociology, Vol 14, pp 319-340.

Lippman, S. A. \& Rumelt, R. P. (1982) "Uncertain imitability: An analysis of interfirm differences in efficiency under competition", Bell Journal of Economics, Vol 13, pp 418-438.

Nonaka, I. (1994) "A dynamic theory of organizational knowledge creation", Organization Science, Vol 5, pp 14-37.

Shannon, C. \& Weaver, W. (1949) The mathematical theory of communication, University of Illinois Press, Chicago, IL.

Szulanski, G. (1995) Appropriating rents from existing knowledge: Intra-firm transfer of best practice,UMI Dissertation, Fontainebleau: INSEAD.

Szulanski, G. (1996) "Exploring internal stickiness: Impediments to the transfer of best practice within the firm," Strategic Management Journal, Vol 17: Special Issue, pp 27-43. 
Szulanski, G. (2000) "The process of knowledge transfer: A diachronic analysis of stickiness", Organizational Behavior and Human Decision Processes, Vol 82, No 1, pp 9-27.

Timbrell G. \& Gable, G. (2001) “The SAP Ecosystem: A Knowledge Perspective”, Proceedings of the Information Resources Management Association International Conference, 20-23 May, Toronto, Canada

Zaltman, G., Duncan, R. \& Holbek, J. (1973) Innovations and Organizations, Wiley, New York, USA. 
Appendix One - Modified Codification Instrument

\begin{tabular}{|c|c|}
\hline $\begin{array}{l}\text { Constructs } \\
\text { (Szulanksi, 1995a) }\end{array}$ & Measurement Items \\
\hline $\begin{array}{l}\text { Causal } \\
\text { Ambiguity }\end{array}$ & $\begin{array}{l}\text { "Depth of knowledge." } \\
\text { Ambiguity about what factors lead to a successful outcome and/or how they } \\
\text { interact. } \\
\text { Ambiguity about how components of the knowledge work when implemented } \\
\text { in a different environment. } \\
\text { Limits of the knowledge or practice were not fully specified. } \\
\text { Not clear what skills, resources and prerequisites are necessary to successfully } \\
\text { perform the practice. } \\
\text { Lack of adequate documentation exists regarding operating procedures. } \\
\text { Procedures do not describe exactly what people actually do. } \\
\text { Nobody fully understood the concept. }\end{array}$ \\
\hline $\begin{array}{l}\text { Unproven Knowl- } \\
\text { edge }\end{array}$ & $\begin{array}{l}\text { "Degree of conjecture on the utility of the transferred knowledge." } \\
\text { Lack of a proven record of the past usefulness or success of the knowledge or } \\
\text { practice. } \\
\text { The knowledge or practice is not seen as contributing significantly to the or- } \\
\text { ganisation's successful outcomes. } \\
\text { Perceived lack of robustness or legitimacy of knowledge or practice. }\end{array}$ \\
\hline $\begin{array}{l}\text { Source Lacks Moti- } \\
\text { vation }\end{array}$ & $\begin{array}{l}\text { "Motivation of the source unit to support the transfer". } \\
\text { Source did not measure own performance. } \\
\text { Unwilling to share knowledge and what its knowledge limits are. } \\
\text { Poor efforts at communication, planning, documentation, implementation, } \\
\text { training, troubleshooting. } \\
\text { Unwilling to devote time and resources to the transfer. } \\
\text { Source perceives a lack of adequate rewards for transferring knowledge. }\end{array}$ \\
\hline $\begin{array}{l}\text { Source Not Per- } \\
\text { ceived as Reliable }\end{array}$ & $\begin{array}{l}\text { "Degree to which the ... [source] is perceived as reliable". } \\
\text { Perceived lack of expertise and trustworthiness. } \\
\text { Validity of source questioned (whether speaking from experience or is relaying } \\
\text { what someone else has told them). } \\
\text { Source unable to accommodate needs of recipient into the knowledge or prac- } \\
\text { tice being transferred. } \\
\text { Perceived hidden agenda. } \\
\text { Perception that source is unable to achieve superior results. } \\
\text { Perceived instability. } \\
\text { Lacks necessary resources to support the transfer. } \\
\text { Lacks a history of successful transfers. } \\
\text { Advice or demonstration is challenged or resisted by recipient. }\end{array}$ \\
\hline $\begin{array}{l}\text { Recipient Lacks } \\
\text { Motivation }\end{array}$ & $\begin{array}{l}\text { "Motivation of the recipient unit to support the transfer". } \\
\text { Recipient did not measure own performance. } \\
\text { Recipient did not adequately communicate its needs to the source. } \\
\text { Recipient did not plan and implement adequate supporting arrangements. } \\
\text { Recipient did not assign personnel full-time to the transfer. } \\
\text { Recipient did not assign personnel to be trained. } \\
\text { Recipient did not troubleshoot. } \\
\text { Recipient did not ensure that people know their jobs \& consent to continue do- } \\
\text { ing them. } \\
\text { Users or staff reluctant to accept knowledge from outside. } \\
\text { Not invented here syndrome. }\end{array}$ \\
\hline $\begin{array}{l}\text { Recipient Lacks } \\
\text { Absorptive Capacity }\end{array}$ & $\begin{array}{l}\text { "Ability of the recipient ... to identify, value and apply new knowledge." } \\
\text { Inability to value, assimilate or apply transferred knowledge due to limited pre- } \\
\text { existing stock of knowledge. } \\
\text { Lack of a common language/terminology to deal with the knowledge or prac- } \\
\text { tice. } \\
\text { Lacks vision of what trying to achieve through the transfer. }\end{array}$ \\
\hline
\end{tabular}




\begin{tabular}{|c|c|}
\hline & $\begin{array}{l}\text { Lacks information on state of the art practice. } \\
\text { Lacks clear division of roles and responsibilities to implement. } \\
\text { Lacks necessary skills to implement. } \\
\text { Recipient lacks the technical and managerial competence to absorb the knowl- } \\
\text { edge or practice. } \\
\text { Recipient does not know who can help solve specific problems or provide spe- } \\
\text { cific information. } \\
\text { Recipient did not cope with the training methodology. } \\
\text { Recipient did not develop adequate equipment and processes. } \\
\text { Recipient did not hire the right people. } \\
\text { Relative inexperience of recipient. } \\
\text { Recipient unable to understand a different approach. } \\
\text { Inability to locate relevant process owner. }\end{array}$ \\
\hline $\begin{array}{l}\text { Recipient } \\
\text { Lacks } \\
\text { Retentive } \\
\text { Capacity }\end{array}$ & $\begin{array}{l}\text { "Ability of the recipient ... to routinize the use of new knowledge." } \\
\text { Lacks ability/persistence to retain transferred knowledge. } \\
\text { Lacks ability to institutionalise use of the new knowledge. } \\
\text { Discontinued use of the transferred knowledge. } \\
\text { Reversion to the status quo. } \\
\text { Personnel were not periodically retrained. } \\
\text { Recipient lacks mechanisms to detect malfunctions of practice. } \\
\text { Personnel uncertain how they will be rewarded for good performance. } \\
\text { Lack of a clear focal point in the organisation for the knowledge. } \\
\text { Ability to unlearn old routines and superceded knowledge. }\end{array}$ \\
\hline $\begin{array}{l}\text { Barren Organisa- } \\
\text { tional Context }\end{array}$ & $\begin{array}{l}\text { "Degree to which the organizational context supports the development of } \\
\text { transfers." } \\
\text { Organisational context hinders knowledge transfers. } \\
\text { Lack of detailed, timely and comparable performance measures. } \\
\text { Standard policies about the practice not enforced. } \\
\text { Lack of constant pressure to improve performance. } \\
\text { Difficult to justify time and money spent assimilating the transferred knowl- } \\
\text { edge. } \\
\text { Low acceptance for copying and adapting knowledge or practices. } \\
\text { Loss of status if ask for help or need to learn from someone else. } \\
\text { External help or advice not valued or encouraged. } \\
\text { Specific knowledge transferred was not valued. } \\
\text { Lack of opportunities for transfer of the needed knowledge. }\end{array}$ \\
\hline $\begin{array}{l}\text { Arduous Relation- } \\
\text { ship }\end{array}$ & $\begin{array}{l}\text { Difficulties with the "ease of communication and intimacy of the relation- } \\
\text { ship". } \\
\text { Lack of easy or open communication btw source and recipient. } \\
\text { Laboriousness of interaction. } \\
\text { Language problems. } \\
\text { Collaboration avoidance. }\end{array}$ \\
\hline
\end{tabular}

